\title{
La evaluación de competencias profesionales en un modelo de formación interdisciplinaria a nivel posgrado
}

Patricia Muñoz Ledo Rábago ${ }^{1}$

\section{Introducción}

En el contexto actual, la universidad pública debe enfrentar el reto de adecuarse a la llamada sociedad del conocimiento, caracterizada por la complejidad, la incertidumbre, el avance científico, las tecnologías de la información y la comunicación. Estos elementos deben orientar las adecuaciones de los actuales modelos universitarios ante la exigencia de mejorar la calidad de sus programas formativos y servicios que ofrece a la sociedad a través de sus funciones sustantivas. En este sentido, las políticas educativas se han estructurado en torno a la evaluación de su calidad, una de las dimensiones actuales más importantes en este proceso lo ha constituido el concepto de competencia.

1 Universidad Autónoma Metropolitana-X/Laboratorio de Seguimiento del Neurodesarrollo INP-UAM. 


\section{El concepto de competencia}

Son diversas las aproximaciones teóricas que han sustentado el concepto de competencias. El actual debate tiene relación con su origen funcionalista-eficientista de la acción profesional como respuesta a las exigencias del mundo laboral. Este ámbito utilitario centrado en la capacitación de los universitarios para el mercado laboral es cuestionado por visiones más integradoras derivadas de las filosofías del sujeto como agente activo en su proceso formador (pedagogía activa, centrada en el alumno o la pedagogía de resolución de problemas). En 1996, la UNESCO, a través del Informe Delors de la Comisión Internacional de Educación para el siglo xxI, estableció la necesidad de dar paso de la capacitación a la competencia.

La competencia es una construcción resultado de una combinación pertinente de varios recursos (conocimientos, procedimientos y actitudes). Para saber actuar, es necesario integrar y movilizar los recursos necesarios y saber integrarlos, transferirlos y aplicarlos a contextos o situaciones complejas. Por tanto, competencia consistirá en la intervención eficaz en los diferentes ámbitos de la vida mediante acciones en las que se movilizan, al mismo tiempo y de manera interrelacionada, componentes actitudinales, procedimentales y conceptuales (Zabala y Arnau, 2008).

Las nuevas aportaciones al concepto de competencias parten de las consideradas pedagogías transformadoras; es el caso de la pedagogía de la integración y su propuesta basada en "situaciones" o problemas de la realidad concreta (competencias basadas en la solución de problemas). Proponen estrategias y metodologías activas basadas en la acción del alumno. Rompen con la tradicional forma de evaluar competencias sólo como productos (evaluación sumativa), al integrar modelos de evaluación formativa, evaluación auténtica o lo que sería el paradigma de la evaluación comprensiva.

En el contexto del modelo Xochimilco, las competencias no podrán definirse al margen de situaciones problemas de la realidad en función de las cuales el alumno pueda reflexionar, 
contextualizar, cuestionar, modificar y construir nuevos conocimientos, transformando sus esquemas de pensamiento y acción práctica con la finalidad de enriquecer su actuación profesional en el campo donde deberá incidir en la solución de los problemas identificados. Competencias que desde la epistemología genética significarían operar sobre el objeto de conocimiento para transformarlo y no extraer simplemente una copia (Piaget, 1977).

El concepto de competencias considera definiciones y elementos presentes en diversas conceptualizaciones que han permitido construir un instrumento orientado a la evaluación de competencias del alumno en momentos diferenciables de desempeño o actuación formativa, es decir, durante el seguimiento del alumno en el programa de posgrado. Los elementos que integran el concepto de competencia que se propone son los siguientes.

- Qué: esquema de pensamiento y acción que integra conocimientos, habilidades y actitudes.

- Para qué: identificar y solucionar problemas ligados al campo profesional.

- Por medio de qué: movilizar recursos cognitivos y estrategias procedimentales diferenciadas (de acuerdo a la especificidad y complejidad del problema identificado).

- Dónde: en escenarios reales de la acción profesional.

\section{La evaluación de competencias}

Evaluar por competencias implica una estrategia que permita conocer la calidad del proceso y los logros alcanzados en el proyecto formativo. En este sentido, evaluar competencias, "es evaluar procesos en la resolución de situaciones-problema" (Zabala y Arnau, 2008). Conocer el nivel de dominio de una competencia desarrollada por los alumnos es una tarea compleja, pues implica que a partir de situaciones-problema en contextos reales se debe disponer de los medios de evaluación específicos para cada uno de los componentes de la competencia por evaluar. 
Evaluar competencias de servicio-investigación-docencia se refiere a la oportunidad que tienen los alumnos durante sus actividades clínicas y de investigación para poner en práctica sus conocimientos, habilidades y actitudes al abordar y resolver problemas del campo profesional en contextos reales de actuación.

La evaluación de competencias en el posgrado implica identificar procesos de construcción por aproximaciones sucesivas de complejidad creciente, movilizar saberes o esquemas de pensamiento y acción, cambios conceptuales, procedimentales y actitudinales que pueden ser observados y por tanto evaluados durante el proceso formativo de los alumnos. Los conocimientos se refieren a las capacidades para pensar y saber (saber conocer). Dependen de la estructura mental y los procesos cognitivos del pensamiento. Están ligados a la adquisición de contenidos de aprendizaje, elementos necesarios en toda transformación de la estructura conceptual o esquemas de pensamiento que guían la acción. No se trata de conocer o adquirir conocimientos por conocer, sino de conocer para transformar una realidad problematizada. En la enseñanza situada, los conocimientos que adquiere el alumno deben permitir realizar actividades demandadas por el entorno, actuar en situaciones concretas. Conocer no se presenta separado del aplicar y del hacer; la teoría no es disyuntiva de la práctica, los conocimientos cobran significado a través de las acciones (Valladares, 2011). Las actitudes se pueden entender como una predisposición afectiva y motivacional que se requiere para el desarrollo de una determinada acción, integran componentes cognitivos y un compromiso ético actitudinal (ser). Se refieren al actuar con autonomía, juicio y responsabilidad personal. Las habilidades aluden a los esquemas de acción, para actuar y hacer, aplicar conocimientos adquiridos (saber hacer), buscar nuevas soluciones a los problemas planteados, hacer frente a situaciones previstas e imprevistas (creatividad).

En la acción humana, para dar respuesta a un problema no se presentan por separado los conocimientos, habilidades y actitudes, no se movilizan piezas independientes, las competencias que se expresan en la acción resultan de la integración de 
lo conceptual (saber), lo procedimental (saber hacer) y lo actitudinal (saber ser).

\section{Propuesta de instrumento para evaluar competencias}

El diseño del instrumento partió de la reflexión de las competencias que pretende formar el programa a partir del modelo Xochimilco, en tres dimensiones o campos de acción profesional; servicio, investigación y docencia.

Las competencias de servicio o clínicas se definen como el conjunto de capacidades que permiten resolver problemas que se enfrentan en la práctica clínica cotidiana (detección, diagnóstico e intervención).

Las competencias científicas o de investigación hacen referencia en un sentido integrador a acciones orientadas a producir, transferir y aplicar nuevos conocimientos útiles y pertinentes a las problemáticas específicas que atañen a las distintas esferas de la sociedad (Valladares, 2011).

Las competencias docentes pueden definirse como el conjunto de capacidades individuales del profesional para movilizar recursos cognitivos relacionados con su desempeño en la planeación, realización y evaluación de procesos educativos ante situaciones problema de docencia específica (Marín y Guzmán, 2010).

Se buscó la congruencia entre el concepto de competencias y su evaluación en prácticas clínicas y de investigación (actividades instrumentales). Cada dimensión de competencias o campos de la acción profesional de servicio, investigación y docencia (generación, aplicación y difusión del conocimiento) integra un conjunto de competencias específicas y sus indicadores de logro, estos últimos con base en niveles de complejidad creciente.

Para cada competencia específica se establecieron varios indicadores de logro que permiten evaluar el grado de dominio de los distintos componentes de la competencia con que el alumno realiza o expresa la competencia (esquemas de acción), 
al aplicarlos a situaciones reales en contextos concretos de la práctica clínica. Los esquemas de acción no son excluyentes, permiten integrar varios componentes de las competencias (conceptual, procedimental y actitudinal). Los indicadores establecen una secuencia formativa lógica en momentos diferenciables de la complejidad que implica el logro o dominio de la competencia (los niveles de complejidad fueron organizados en seis periodos trimestrales).

Con base en la propuesta de Posada (2003), en la elaboración de los indicadores se consideraron tres componentes: La acción que debe ejecutarse, por ejemplo "identifica"; el objeto sobre el cual se ejerce la acción, por ejemplo, "limitantes sociales como riesgos en los procesos que derivan a restricciones para la participación social"; y la condición referida al contexto o situación específica en que se evalúa el indicador de la competencia, por ejemplo, "en los casos que atiende". En la actualidad, la propuesta del instrumento se aplica a alumnos del posgrado en Rehabilitación Neurológica (formato de evaluación por competencias de la maestría en Rehabilitación Neurológica UAM-X).

\section{Referencias}

Marín, R. y Guzmán, I. (2010). Formación-Evaluación: Una propuesta para el desarrollo y evaluación de competencias docentes. En Cisneros, C., García, C., Luna, S. y Marín, R. (Eds.), Evaluación de competencias docentes en la educación superior (169-210). México: Plaza y Valdés.

Piaget, J. (1977). Psicología y Pedagogía. Barcelona: Ariel.

Posada, A.R. (2003). Formación superior basada en competencias, interdisciplinariedad y trabajo autónomo. Revista Iberoamericana de Educación. Recuperado de http://www. rieoei.org/deloslectores/648Posada.pdf.

Valladares, L. (2011). Las competencias en la educación científica. Perfiles Educativos, XXXIII(132): 158-182.

Delors, J. (1996). Informe Delors. La educación encierra un tesoro. Madrid: unEsCo-Santillana. 
Formato de evaluación por competencias. Maestría en Rehabilitación Neurológica. México, D.F.: México. UAM-X. Documento interno s/f.

Zabala, A. y Arnau, L. (2008). Once ideas claves. Cómo aprender y enseñar competencias. México: Graó/Colofón. 
